\author{
ARTIGO \\ do/ https://doi.org/10.22481/rpe.v16i43.6948
}

\title{
A EDUCAÇÃO PROFISSIONAL NO BRASIL E EM PORTUGAL: RELAÇÃO COM O SETOR PRODUTIVO
}

\author{
PROFESSIONAL EDUCATION IN BRAZIL AND PORTUGAL: RELATIONSHIP WITH \\ THE PRODUCTIVE SECTOR
}

\begin{abstract}
EDUCACIÓN PROFESIONAL EN BRASIL Y PORTUGAL: RELACIÓN CON EL SECTOR PRODUCTIVO
\end{abstract}

Valdivina Alves Ferreira

Universidade Católica de Brasília - Brasil

Luísa Cerdeira

Instituto de Educação da Universidade de Lisboa - Portugal

\begin{abstract}
Resumo: O objetivo do texto é refletir sobre a relação entre a Política de Educação Profissional e o setor produtivo a partir de documentos normativos do Brasil e de Portugal. A Educação Profissional é uma modalidade de ensino que, ao longo das décadas, se apresenta como um desafio, uma vez que, de um lado, há um grupo de pesquisadores que defendem a formação integral do homem, e de outro, existem os documentos normativos que legitimam esse processo de formação voltado para a qualificação de força de trabalho para o atendimento das demandas do setor produtivo em diferentes contextos históricos. Esta polaridade é observada há vários séculos no discurso dos pesquisadores e no registro contido nos documentos normativos que tratam sobre a temática. Este artigo teve como procedimentos metodológicos a pesquisa bibliográfica e documental. Os principais resultados apontam que mesmo que a Educação Profissional reforce a finalidade do sistema capitalista no atendimento às demandas para acompanhar a produção, distribuição e comercialização de bens, serviços e produtos, é possível a oferta de formação integral dos estudantes observada nos dois países.
\end{abstract}

Palavras-chave: Educação profissional; Setor produtivo; Formação integral.

\begin{abstract}
The purpose of the text is to reflect on the relationship between the Professional Education Policy and the productive sector based on normative documents from Brazil and Portugal. Professional Education is a teaching modality that, over the decades, presents itself as a challenge, since, on the one hand, there is a group of researchers who defend the integral formation of man and on the other there are the normative documents that legitimize this training process aimed at qualifying the workforce to meet the demands of the productive sector in different historical contexts. This polarity has been observed for several centuries in the researchers' discourse and in the record contained in the normative documents dealing with the theme. This article had as methodological procedures the bibliographic and documentary research. The main results point out that even though Professional Education reinforces the purpose of the capitalist system in meeting the demands to accompany the production, distribution
\end{abstract}


and commercialization of goods, services and products, it is possible to offer comprehensive training for students observed in both countries.

Keywords: Professional education; Productive sector; Comprehensive training.

Resumen: El propósito del texto es reflexionar sobre la relación entre la Política de Educación Profesional y el sector productivo basada en documentos normativos de Brasil y Portugal. La Educación Profesional es una modalidad de enseñanza que, a lo largo de las décadas, se presenta como un desafío, ya que, por un lado, hay un grupo de investigadores que defienden la formación integral del hombre y por otro están los documentos normativos que legitiman este proceso de capacitación destinado a calificar a la fuerza laboral para satisfacer las demandas del sector productivo en diferentes contextos históricos. Esta polaridad se ha observado durante varios siglos en el discurso de los investigadores y en el registro contenido en los documentos normativos que tratan el tema. Este artículo tuvo como procedimientos metodológicos la investigación bibliográfica y documental. Los principales resultados indican que, aunque la Educación Profesional refuerza el propósito del sistema capitalista de satisfacer las demandas de acompañar la producción, distribución y comercialización de bienes, servicios y productos, es posible ofrecer una capacitación integral para los estudiantes observados en ambos países.

Palabras clave: Educación professional; Sector productivo; Formación integral.

\section{Introdução}

A Educação Profissional é uma modalidade de ensino que, ao longo das décadas, se apresenta como um desafio, pois que, de um lado, há um grupo de pesquisadores que defendem a formação integral do homem, e de outro, existem os documentos normativos que legitimam esse processo de formação voltado para a qualificação de força de trabalho para o atendimento das demandas do setor produtivo em diferentes contextos históricos.

Assim, este texto tem como objetivo refletir sobre a relação entre a Política de Educação Profissional e o setor produtivo a partir de documentos normativos no Brasil e em Portugal. Buscou-se na pesquisa qualitativa, com procedimentos de pesquisa bibliográfica e documental, levantar nos principais documentos normativos os registros que mostram a intencionalidade da oferta da Educação Profissional no âmbito escolar, tanto no Brasil quanto em Portugal.

Os principais resultados apontam que mesmo que a Educação Profissional reforce a finalidade do sistema capitalista no atendimento às demandas para acompanhar a produção, distribuição e comercialização de bens, serviços e produtos, é possível a oferta de formação integral aos estudantes. Essa formação integral é defendida por Moura (2007), Saviani (2004, 2007), Frigotto, Ciavatta e Ramos (2011) no Brasil, e por Rodrigues (2010), Azevedo (2014), Formosinho e Machado (2009) e Roldão (2009) em Portugal. 


\section{A Educação Profissional no Brasil: os documentos normativos e sua relação com o setor produtivo}

A ideia da Educação Profissional surge no Brasil a partir do período colonial por intermédio da Companhia de Jesus, constituída pelos jesuítas (FONSECA, 2013). As evidências para a afirmação encontram respaldo no Plano de Estudos apresentado por Manuel da Nóbrega para o Aprendizado Profissional e Agrícola. O Plano continha instrução para o aprendizado de português (para o indígena), prosseguia com a doutrina cristã, a escola de ler e escrever e a opção do canto orfeônico e música instrumental, e culminava com o aprendizado profissional e agrícola. Já o ensino da gramática latina se destinava aos que realizariam seus estudos superiores na Europa (Universidade de Coimbra). Segundo Saviani (2007), havia uma preocupação realista com a Colônia, considerando as suas condições na época: a escassez de trabalhadores preparados para as atividades manuais que atendiam necessidades imediatas.

A Companhia de Jesus foi expulsa em 1759 pelo Marquês de Pombal, Secretário de Estado do rei de Portugal, D. José I. Todos os integrantes da Companhia de Jesus foram expulsos de Portugal e suas colônias. No Brasil todos os jesuítas foram presos e enviados a Portugal. Todos os bens móveis e imóveis foram confiscados. A expulsão dos jesuítas exigiu de Portugal uma reforma educacional que ficou conhecida como "As Reformas Educacionais de Pombal”. Estas reformas tinham três objetivos: Trazer a educação para o controle do Estado, secularizar a educação e padronizar o currículo (FONSECA, 2013). Diretores ocupariam o lugar dos jesuítas e duas escolas públicas deveriam ser implantadas em cada aldeia indígena. Todos os estudantes deveriam falar a língua portuguesa. Era proibido aos índios falarem a própria língua. Na implantação da instrução pública foram criadas as aulas régias (aulas avulsas).

Eduardo Monteiro Gonzaga do Monti, em 2018, ao analisar a reforma do ensino que ocorreu no século XVIII em Portugal e suas colônias, por meio do Marquês de Pombal, mostra que o formato das aulas régias compreendia essencialmente

[...] um significativo afastamento das práticas e dos materiais que o Marquês de Pombal entendia como o método antigo e ultrapassado que deveria ser modernizado com termos simples, claros e de maior eficácia, como os que eram praticados naquele período em alguns países da Europa. Assim, no projeto de ensino pombalino, o diretor dos estudos também era responsável por não permitir o professor concursado, funcionário do governo, a fazer uso dos métodos já utilizados nos domínios do reino de Portugal nas escolas fundadas pela Companhia de Jesus. (MONTI, 2018, p. 86).

Os ofícios considerados menos nobres, por se constituírem em atividades mecânicas, como alfaiataria, carpintaria e pintura, para os meninos, e as atividades de costura e bordado, 
para as meninas, eram realizados na residência dos próprios professores ou nos locais de trabalho. Segundo Monti (2018, p. 87), os professores responsáveis por tais aulas lidavam, sobretudo, “com crianças e jovens enviados pelos asilos de órfãos e por famílias com escassos recursos, incluindo os filhos de escravos".

O século XVIII foi marcado por grandes transformações na sociedade portuguesa, consubstanciadas pelas Reformas Pombalinas, que compreendiam os setores econômicos, administrativos e educacional, tanto em Portugal quanto em suas colônias. Com a reforma, o objetivo da política colonial portuguesa era passar da etapa do processo mercantil para a economia movida pela indústria. Ao falar sobre a situação econômica e política dos países colonizadores, "fica claro a posição de Portugal frente às demais potências da época, concluindo que a Inglaterra a partir do século XVI e, principalmente, do século XVII, já era uma nação burguesa e industrial estando à frente das demais" (SECO; AMARAL, 2020, p. 2).

A Reforma Pombalina visava possibilitar meios para a recuperação da economia por meio da concentração do poder no sentido de modernizar a cultura portuguesa, iniciando assim uma tentativa de transformar Portugal em uma metrópole capitalista, a exemplo da Inglaterra, e para alcançar tal propósito a modernização de sua maior colônia, o Brasil, se fazia necessário. Seco e Amaral (2020, p. 3) apontam em sua pesquisa que a "ideia de pôr o reinado português em condições econômicas tais que lhe permitissem competir com as nações estrangeiras era talvez a mais forte razão das reformas pombalinas". Com a reforma em curso, a exploração das riquezas no Brasil Colônia foi direcionada para aumentar os ganhos de Portugal e assim contribuir fortemente para alcançar os objetivos pombalinos referentes à economia portuguesa ${ }^{1}$.

No entanto, o que as pesquisas mostram é que tanto o Plano de Estudos de Nóbrega quanto a reforma educacional de Pombal não lograram êxito no Brasil Colônia. O Plano de Estudos constituía apenas uma intenção pedagógica que contemplava o aprendizado comercial e agrícola, e não chegou a ser concretizado, e a reforma educacional, que abrangia aulas de desenho e de comércio, não foi totalmente materializada. O que se observa é que os planos de estudo que contemplavam a educação ou formação profissional, ao longo do período colonial, ficaram mais na intenção do que na realização. No entanto, todos eles tiveram, em seu bojo, a perspectiva da utilização da força de trabalho da população para as demandas do setor produtivo na época.

No início do século XIX, em 1808, com a chegada da família real ao Brasil, há um movimento de organização do ensino no Brasil. São criadas as primeiras instituições de ensino

\footnotetext{
${ }^{1}$ Para mais detalhes sobre as intenções nas Reformas Pombalinas consultar: http://www.histedbr.fe.unicamp.br/navegando/periodo_pombalino_intro.html\#_ftn2
} 
superior no país, instituições não teológicas. As instituições criadas eram destinadas à formação de pessoas para executarem funções qualificadas no exército e em atividades na administração do Estado. Foi criado por D. João VI o Colégio das Fábricas, o primeiro espaço construído pelo poder público que tinha como principal objetivo o atendimento à educação dos artistas e dos aprendizes que vieram de Portugal. Outra iniciativa para atender às demandas da educação profissional foi a criação das Casas de Educandos Artífices instaladas nas províncias.

Após quarenta anos da chegada da família real ao Brasil foram criadas as escolas de ofícios, mantidas pelo Estado, e tinham como finalidade o ensino de trabalhos manuais e artesanais a órfãos e desvalidos da sorte. Gomes (2013) refere que os ofícios aprendidos eram tipografia, encadernação, alfaiataria, carpintaria. Em 1856, a sociedade civil cria os liceus de artes e ofícios, com acesso livre, exceto aos escravos. Para a autora, a criação das primeiras instituições de educação profissional, no Brasil, teve um caráter assistencial.

O Decreto n 7.566/1909, do então presidente da República, Nilo Peçanha, "Crêa nas capitaes dos Estados da Republica Escolas de Aprendizes Artifices, para o ensino profissional primario e gratuito". Destaca-se o excerto do texto, conforme segue:

Que para isso se torna necessario, não só habilitar os filhos dos desfavorecidos da fortuna com o indispensavel preparo technico e intellectual, como fazel-os adquirir habitos de trabalho proficuo, que os afastará da ociosidade ignorante, escola do vicio e do crime; Que é um dos primeiros deveres do Governo da Republica formar cidadãos uteis à Nação. (BRASIL, 1909).

O ensino noturno constava no artigo $8^{\circ}$ do documento e prescrevia que em cada

Escola de Aprendizes Artifices dous cursos nocturnos: primario, obrigatorio para os alumnos que não souberem ler, escrever e contar, e outro de desenho, tambem obrigatorio para alumnos que carecerem dessa disciplina para o exercicio satisfactorio do officio o que aprenderem. (BRASIL, 1909).

Para Kuenzer (2007, p. 27), essas escolas tinham "a finalidade moral de repressão: educar pelo trabalho, os órfãos, pobres, e desvalidos da sorte, retirando-os das ruas". Mesmo considerando a criação dessas escolas uma tentativa de formalização do ensino profissional no Brasil, foi direcionada à classe pobre da sociedade, o que demonstra um preconceito social para essa modalidade de ensino. Gomes (2013, p. 63) afirma que a educação profissional, no Brasil, foi marcada por um ensino precário, sendo direcionada para a formação de força de trabalho para atender "às necessidades do sistema produtivo, enquanto o ensino acadêmico era proporcionado para a futura elite dirigente do país".

Com o início da industrialização no Brasil, um período de transformações econômicas no modo de produção, a partir da década de 1930, cresce a demanda social por educação. Com 
a criação do Ministério da Educação e Saúde Pública, em 1930, o então ministro da Educação emitiu uma série de Decretos, conhecidos como a Reforma Francisco Campos, dando origem ao ensino secundário, implantando o currículo seriado e enciclopédico (GOMES, 2013). Um dos Decretos (2.0158/1931) cria o ensino comercial e regulamenta a profissão de contador.

$\mathrm{Na}$ efervescência do movimento da Escola Nova, movimento com ideias de renovação da escola que se disseminou em vários países, inclusive no Brasil, decorrente das mudanças efetivadas no processo de desenvolvimento capitalista com seus valores, houve a necessidade, segundo alguns defensores, de mudanças na escola. Assim foi promulgada, pelo presidente Getúlio Vargas, em 10 de novembro de 1937, mesmo dia em que foi implantada a ditadura do Estado Novo, a quarta Constituição do Brasil e a terceira da República. Em seu artigo 129 preceitua:

O ensino prevocacional profissional destinado às classes menos favorecidas é, em materia de educação, o primeiro dever do estado. Cumpre-lhe dar execução a esse dever, fundando institutos de ensino profissional e subsidiando os de iniciativa dos Estados, dos Municipios e dos indivíduos ou associações particulares e profissionais. (BRASIL, 1937).

No mesmo artigo 129 da Constituição de 1937 se estabelece:

E' dever das industrias e dos syndicatos economicos crear, na esphera da sua especialidade, escolas de aprendizes, destinadas aos filhos de seus operarios ou de seus associados. A lei regulará o cumprimento desse dever e os poderes que caberão ao estado sobre essas escolas, bem como os auxilios, facilidades e subsidios a lhes serem concedidos pelo poder publico. (BRASIL, 1937).

O que se observa no contexto da política econômica da época é o movimento de fortalecimento da política de substituição de importações pela produção interna e a procura de bases para estabelecer a indústria. As medidas econômicas do período tinham características nacionalistas que foram associadas ao estabelecimento de relações entre o Governo Vargas e os Estados Unidos. Essa relação tornou possível ao governo brasileiro conseguir vultosos empréstimos estadunidenses que financiaram o estabelecimento de infraestrutura indispensável ao desenvolvimento do país (BASTOS, 2011).

Assim, é possível apontar que, no Governo Vargas (1930-1945), essa preocupação foi legitimada pela Reforma Capanema, com o nome de Leis Orgânicas da Educação (1942), um conjunto de vários Decretos que estruturou o ensino industrial, reformou o ensino comercial e criou o Serviço Nacional de Aprendizagem Industrial (Senai), como também trouxe mudanças no ensino secundário e no ensino comercial e agrícola (SCHWARTZMAN; BOMENY; COSTA, 2000, p. 205). 
Nesse contexto destaca-se o Decreto $n^{\circ} 4.073$, de 30 de janeiro de 1942, que determina, em seu texto, que o ensino industrial deveria atender aos "interesses das empresas, nutrindo-as, segundo as suas necessidades crescentes e mutáveis, de suficiente e adequada mão de obra"; o texto dispõe ainda, em seu artigo $4^{\circ}$, que o ensino industrial, no que tange à preparação profissional do trabalhador, tem o propósito de "formar profissionais aptos ao exercício de ofícios e técnicas nas atividades industriais" e ainda "dar a trabalhadores jovens e adultos da indústria, não diplomados ou habilitados, uma qualificação profissional que lhes aumente a eficiência e a produtividade" (BRASIL, 1942). Os autores ressaltam que nessa reforma da educação as políticas eram prescritas obedecendo a uma ordem que priorizava uma "educação para a elite e outra educação para os jovens que comporiam o grande exército de trabalhadores necessários à utilização da riqueza potencial da nação e outra ainda para as mulheres”.

Na década de 1960 foi aprovada a primeira Lei de Diretrizes e Bases da Educação Nacional, a Lei $\mathrm{n}^{\circ}$ 4.024, de 20 de dezembro de1961 (BRASIL, 1961), que em seu artigo 47 trazia toda uma prescrição para o ensino técnico com cursos que atendiam à agricultura, à indústria e ao comércio. Esse artigo foi todo revogado pela Lei $\mathrm{n}^{\circ} 5.692 / 71$, com a reforma do ensino de $1^{\circ}$ e $2^{\circ}$ graus (BRASIL, 1971). O que se observa, mais uma vez, é que as políticas da educação brasileira, por meio da reforma, buscaram atender à entrada de capital internacional e ao grande desenvolvimento econômico que forçou o país a buscar, no campo da política pública de educação, a formação de um grande contingente de técnicos que pudessem atender à demanda da força de trabalho vigente. Ciavatta e Ramos (2011, p. 30) afirmam que durante o período em que vigorou o "projeto nacional-desenvolvimentista e a fase do pleno emprego, preparar para o mercado de trabalho foi realmente a principal finalidade do ensino médio [...]".

A Lei $n^{\circ}$ 9.394/1996, em seus artigos 39 e 40, prescreve que a educação profissional deve ser ofertada mediante a necessidade de atendimento ao mercado de trabalho, podendo ser “desenvolvida em articulação com o ensino regular ou por diferentes estratégias de educação continuada, em instituições especializadas ou no ambiente de trabalho" (BRASIL, 1996). A regulamentação dos artigos 39 a 42, sobre a modalidade de educação profissional, materializouse com o Decreto presidencial no 2.208/1997, no governo de Fernando Henrique Cardoso. Em seu artigo $1^{\circ}$, incisos I a IV, constam como objetivos:

I - promover a transição entre a escola e o mundo do trabalho, capacitando jovens e adultos com conhecimentos e habilidades gerais e específicas para o exercício de atividades produtivas; II - proporcionar a formação de profissionais, aptos a exercerem atividades específicas no trabalho, com escolaridade correspondente aos níveis médio, superior e de pós-graduação; III - especializar, aperfeiçoar e atualizar o trabalhador em seus conhecimentos 
tecnológicos; IV - qualificar, reprofissionalizar e atualizar jovens e adultos trabalhadores, com qualquer nível de escolaridade, visando a sua inserção e melhor desempenho no exercício do trabalho. (BRASIL, 1997)

O Decreto legisla sobre a modalidade da educação profissional e tecnológica e marca, mais uma vez, a força do modelo neoliberal, assegurando as condições para adequar e ajustar a educação às demandas exigidas no mercado de trabalho. Pesquisas mostram que a concepção produtivista de educação marcou a implantação e implementação da LDB, Lei nº 9.394/96, bem como os dispositivos legais, nas políticas educacionais subsequentes (SAVIANI, 2004). Ainda sobre o Decreto n 2.208/1997, Garcia e Lima Filho (2010, p. 44) assinalam que a separação em educação profissional e ensino médio reforça a dualidade que se "estende ao ensino superior, por meio de cursos de tecnologia de duração reduzida, destituídos de aprofundamento científico e tecnológicos e limitados às atividades de ensino". Nesse decreto a "educação profissional de nível técnico terá organização curricular própria e independente do ensino médio, podendo ser oferecida de forma concomitante ou sequencial a este", estabelece o texto legal (BRASIL, 1997).

Encaminhamentos que viabilizassem novas diretrizes aos programas e projetos para sua efetivação eram exigidos pelos agentes do governo e representantes da sociedade civil a partir de 2003. As ações decorrentes das propostas encabeçadas por esses setores culminaram na revogação total do Decreto n ${ }^{\circ}$ 2.208/1997 e a emissão de um novo decreto que até então orienta e regulamenta os artigos 39, 40, 41 da Lei ${ }^{\circ}$ 9.394, de 20 de dezembro de 1996; é o Decreto ${ }^{\circ}$ 5.154, de 23 de julho de 2004, sinalizam Frigotto, Ciavata e Ramos (2005). Nesse documento restabelece-se a integração do ensino médio à educação profissional e tecnológica, de acordo com o que dispõe o artigo 36 da LDB n 9.394/96. Na prática, a nova diretriz regulamenta o que segue:

$\S 1^{\circ}$ A articulação entre a educação profissional técnica de nível médio e o ensino médio dar-se-á de forma: I - integrada, oferecida somente a quem já tenha concluído o ensino fundamental, sendo o curso planejado de modo a conduzir o aluno à habilitação profissional técnica de nível médio, na mesma instituição de ensino, contando com matrícula única para cada aluno; II concomitante, oferecida somente a quem já tenha concluído o ensino fundamental ou esteja cursando o ensino médio, na qual a complementaridade entre a educação profissional técnica de nível médio e o ensino médio pressupõe a existência de matrículas distintas para cada curso, [...] III subsequente, oferecida somente a quem já tenha concluído o ensino médio. (BRASIL, 2004).

Ainda após a publicação do Decreto $\mathrm{n}^{\circ} 5.154$, de 23 de julho de 2004, a política de Educação Profissional e Tecnológica (EPT) do governo continua sinalizando a continuidade da 
materialização da concepção de educação voltada para atender às necessidades do mercado de trabalho, a subordinação do processo educativo, por meio das políticas de educação, colocado a serviço da lógica do mercado. Assim, ainda na gestão do presidente Luiz Inácio Lula da Silva, foi aprovada a Lei n 11.892/2008, que instituiu a Rede Federal de Educação Profissional, Científica e Tecnológica, criando 38 Institutos Federais de Educação, Ciência e Tecnologia (IF). A esses IFs é atribuída a tarefa de ofertar a educação profissional e tecnológica nas diferentes modalidades de ensino, com base na conjugação de conhecimentos técnicos e tecnológicos com as suas práticas pedagógicas, nos termos da Lei (BRASIL, 2008).

Dando sequência à política de expansão da oferta da educação profissional e tecnológica do Governo Lula, a então presidente Dilma Vana Rousseff, eleita em 2011, aprova a Lei ${ }^{\circ}$ 12.513, de 26 de outubro de 2011, que institui o "Programa Nacional de Acesso ao Ensino Técnico e Emprego (Pronatec), a ser executado pela União, com a finalidade de ampliar a oferta de educação profissional e tecnológica, por meio de programas, projetos e ações de assistência técnica e financeira" (BRASIL, 2011). A referida Lei dispõe em seus objetivos o atendimento no que tange a "expandir, interiorizar e democratizar a oferta de cursos de educação profissional técnica de nível médio presencial e a distância e de cursos e programas de formação inicial e continuada ou qualificação profissional”, atendendo prioritariamente

[...] estudantes do ensino médio da rede pública, inclusive da educação de jovens e adultos; trabalhadores; beneficiários dos programas federais de transferência de renda; estudantes que tenham cursado o ensino médio completo em escola da rede pública ou em instituições privadas na condição de bolsista integral, nos termos do regulamento [...]. (BRASIL, 2011).

O Pronatec oferta seus cursos no âmbito das instituições privadas, nos serviços nacionais de aprendizagem - "Sistema S" - nos municípios e nos IFs de todo o Brasil. O que se percebe no texto da lei que institui o Programa é que este está voltado ao atendimento da qualificação profissional com vistas a contemplar as demandas do mercado e atender à emergente necessidade do setor produtivo requerido no modelo neoliberal (CIAVATTA; RAMOS, 2011).

\section{Os Cursos Profissionais em Portugal: os documentos normativos e sua relação com o setor produtivo}

A trajetória da história da Educação Profissional em Portugal foi marcada por avanços e recuos ligados à evolução econômica e política do país. O primeiro passo dessa modalidade 
de ensino foi dado por Marquês de Pombal, em 1759, no então reinado de D. José I, que, por meio do Alvará de 19 de maio desse mesmo ano, criou as escolas técnicas do setor têxtil, atividade que tinha grande centralidade na época. Essa modalidade de ensino ganhou impulso com o Decreto de 1852 que instituiu

[...] o ensino industrial, de que o trabalho físico fazia parte genérica para todas as artes e ofícios e dividiu-o em elementar, secundário e complementar; fundou em Lisboa o Instituto Industrial destinado aos três graus de ensino, e tendo anexos um Museu de Indústria e uma Biblioteca Industrial e oficinas para trabalhadores, e no Porto a Escola Industrial com dois primeiros graus do ensino e a cadeira de química aplicada às artes. (PORTUGAL, 1853).

Essa modalidade de ensino tinha como objetivo atender à demanda de mão de obra especializada para acolher a revolução industrial que avançava no setor econômico de alguns países da Europa, embora ainda a passos lentos em Portugal (MARTINS; PARDAL; DIAS, 2005, p. 79-81). Além desse Decreto de 1852, outro texto legal que se destaca é o Decreto de 1864, que dividia o ensino industrial em ensino geral e em ensino especial para as diferentes artes e ofícios, como registram Martins e Martins (2016, p. 11). Foram criadas escolas industriais e escolas para habilitar diretores de fábricas e oficinas, mestres e condutores de vários tipos de trabalho.

Já na primeira república, o Decreto-Lei $\mathrm{n}^{\circ}$ 5.029, de 5 de dezembro de 1918 (PORTUGAL, 1918, p. 2069-2087), assegura o

[...] livre acesso dos alunos, incluindo os analfabetos (taxas elevadas, por volta dos 70\%) a esse ensino profissional, ao ensino das artes e indústrias regionais. [...] Para além da intenção de um ensino profissionalizante, havia também uma função de controle social, bem presente nos ideais liberais. (MARTINS; MARTINS, 2016, p. 12)

Outras reformas se seguiram a partir de 1918: Decreto-Lei $n^{\circ} 20.420 / 1931$, Decreto ${ }^{\circ}$ 37.028/1948 e Decreto ${ }^{\circ}$ 37.029/1948, sempre contemplando o que está registrado na página 2067 do Diário do Governo $n^{\circ}$ 263, de 5/12/1918. O texto mostra as concepções da época referentes à Educação Profissional da seguinte forma: "na escola está a força, o direito e o futuro dum povo. [...] A missão do ensino [...], o fim utilitário do ensino [...]”, mais adiante encontrase registrado que "o que mais interessa a felicidade de um povo é a sua produção, [...] a força produtiva que são a agricultura e a indústria e a força expansiva que é o comercio", afirmando que essa capacidade de produção só é possível por meio do ensino. E continua no parágrafo seguinte: 
O progresso tem uma unidade social, um fator elementar que é o operário, quer seja o operário de mãos calejadas em trabalhos rudes, quer seja o operário que despende as suas horas em pesquisas científicas, práticas, enfim, o profissional deriva dum conjunto: a harmonia das diversas profissões. (PORTUGAL, 1931).

Em relação ao cidadão, o Decreto-Lei n ${ }^{\circ} 20.420$, de 1931, dispõe que seu valor está relacionado com a sua capacidade laboral, ou seja, "quanto maior for o grau de seu desenvolvimento profissional, o quanto mais sólida for a sua disciplina social, quer dizer, o seu valor variará com a sua capacidade produtiva" (PORTUGAL, 1931).

Com a Revolução dos Cravos ocorrida em 1974, em Portugal, que derrubou uma das ditaduras mais duradouras da história do Ocidente, iniciada em 1926 como regime militar, surgiram discussões, ora referentes à natureza da ditadura derrubada, ora relacionadas ao processo revolucionário e do regime democrático que veio a seguir. Em meio a estes embates, a reformulação do sistema de educação foi medida necessária. Configurou um período de debates ideológicos gerando conflitos sociais que são característicos de uma transição política. Em meio a esses conflitos e debates, os ideais convergiram para um consenso no que se refere ao papel que a educação desempenha para a modernização do país, aponta Rodrigues (2010).

Após doze anos da Revolução dos Cravos, Portugal aderiu à União Europeia. Esta adesão, em 1986, viabilizou grandes financiamentos europeus para a qualificação dos jovens portugueses, o que gerou grandes debates acerca das prioridades a serem consideradas para aplicação desses recursos por meio do Programa de Desenvolvimento da Educação em Portugal. Além disso, houve forte pressão quanto à "qualificação que representavam estes financiamentos externos da União Europeia, o 'exame à política educativa de Portugal', promovido pela OCDE, em 1987, continha como uma das recomendações centrais o investimento na qualificação profissional inicial dos jovens" (AZEVEDO, 2014, p. 14).

Ao visitar a Constituição da República Portuguesa (CRP) de 1976, em seu artigo 70, alínea a, encontra-se que a lei assevera que os “jovens gozam de proteção especial para efetivação dos seus direitos econômicos, sociais e culturais, nomeadamente: no ensino, na formação profissional e na cultura”. Ainda na carta magna deste país, no artigo $74^{\circ}$, ao tratar sobre o Ensino, apresenta como incumbência do Estado "inserir as escolas nas comunidades que servem e estabelecer a interligação do ensino e das atividades econômicas, sociais e culturais". Observa-se que o documento normativo principal, a CRP de 1976, traz em seu texto a ideologia educativa contemplando os ideais de competitividade econômica do país (PORTUGAL, 1976). 
Na década de 1980, fins do século XX, houve um movimento no sentido de discutir uma educação que desenvolvesse competências profissionais em que os jovens escolares portugueses fossem orientados ao mercado de trabalho. Assim, no final de outubro de 1983, o Despacho 194-A/1983 introduziu, de forma imediata, o ensino técnico-profissional nas escolas secundárias, gerando orientações escolares e profissionais que mobilizaram alunos, empresas, os Ministérios da Educação e do Trabalho, afirma Rodrigues (2010). A Lei de Bases do Sistema Educativo (LBSE), Lei n ${ }^{\circ}$ 49/2005, de 30 de agosto, contém as alterações e aditamentos introduzidos, observando a Lei $n^{\circ}$ 46/1986, de 14 de outubro, e a Lei $n^{\circ}$ 115/1997, de 19 de setembro - que em seu artigo $22^{\circ}$, ao tratar da educação profissional, estabelece:

1 - A formação profissional, para além de complementar a preparação para a vida activa iniciada no ensino básico, visa uma integração dinâmica no mundo do trabalho pela aquisição de conhecimentos e de competências profissionais, por forma a responder às necessidades nacionais de desenvolvimento e à evolução tecnológica. (PORTUGAL, 1997).

E ainda dispõe que

[...] 5 - A organização dos cursos de formação profissional deve adequar-se às necessidades conjunturais nacionais e regionais de emprego, podendo integrar módulos de duração variável e combináveis entre si, com vista à obtenção de níveis profissionais sucessivamente mais elevados. (PORTUGAL, 1997).

A relação da Educação Profissional com o setor produtivo encontra uma crítica nas palavras de Carneiro (2004) ao referir que a formação profissional consiste em uma adequação às necessidades conjunturais nacionais, regionais e locais de emprego, o que possibilita ter uma visão da formação profissional como sendo uma escolarização que se materializa em segunda oportunidade, destinada ao mercado de trabalho, ao setor produtivo e dele ficar dependente.

Quanto ao funcionamento dos cursos de formação profissional e módulos, pode ser realizado segundo formas institucionais diversificadas, previstos no artigo $22^{\circ}$ da Lei de Bases do Sistema Educativo de 2005:

a) Utilização de escolas de ensino básico e secundário; b) Protocolos com empresas e autarquias; c) Apoios a instituições e iniciativas estatais e não estatais; d) Dinamização de acções comunitárias e de serviços à comunidade; e) Criação de instituições específicas. (PORTUGAL, 2005).

E no que se refere à conclusão dos estudos, a Lei de Bases do Sistema Educativo traz:

A conclusão com aproveitamento de um módulo ou curso de formação profissional confere direito à atribuição da correspondente certificação. 8 Serão estabelecidos processos que favoreçam a recorrência e a progressão no 
sistema de educação escolar dos que completarem cursos de formação profissional. (PORTUGAL, 2005).

Ainda para situarmos a forma de organização do ensino em Portugal, a Lei de Bases do Sistema Educativo de Portugal, em seu capítulo II, artigo $4^{\circ}$, registra que a Organização Geral do Sistema Educativo “compreende os ensinos básico, secundário e superior, integra modalidades especiais e inclui actividades de ocupação de tempos livres". O ensino secundário tem a duração de três anos, nos quais os estudantes podem realizar cursos científicohumanísticos mais vocacionados para o prosseguimento de estudos ou cursos de caráter profissional. Após a conclusão do curso secundário, os estudantes podem realizar Cursos de Especialização Tecnológica (CET), que combinam a teoria e formação para o trabalho (PORTUGAL, 2005).

Observa-se que há uma dualidade, ao mencionar na própria lei e ao distinguir o "ensino regular" - prosseguimento de estudos das "modalidades especiais de ensino" - como é o caso dos cursos de "formação profissional”. Justino (2017) considera que essa concepção curricular, ao definir um currículo mais aligeirado e pretensamente menos exigente aos cursos profissionais, dificulta a promoção da formação integral do estudante. Continua a firmar que a concretização desses "cursos nem sempre corresponde às oportunidades de inserção no mercado de trabalho por claro desajuste entre os conhecimentos e competências prescritas e as necessidades das empresas e demais empregadores (JUSTINO, 2017, p. 31).

Os documentos normativos consultados em relação à trajetória da Educação Profissional, tanto no Brasil quanto em Portugal, mostram que essa modalidade de ensino sempre esteve a serviço dos meios de produção e subordinada aos interesses da elite predominante em cada período histórico. Constata-se que as ideias do Marquês de Pombal, em 1759, para impulsionar a economia em Portugal e suas colônias tinha a educação como aliada aos seus interesses. A Reforma Pombalina, por meio das aulas régias, direcionou a educação colocando-a a serviço dos grandes interesses do reino português em busca da modernização, por meio do Alvará de 28 de junho de 1759 (PORTUGAL, 1759). Esse marco inicial da Educação Profissional no século XVIII foi comum aos dois países no que se refere ao documento em questão.

Outra situação encontrada nos documentos normativos foi a questão da dualidade do ensino. Os dados localizados nos documentos mostram que a educação sempre esteve a serviço daqueles que detêm o poder econômico. Observa-se que a oferta de educação privilegia nos documentos a escola implementada para atender aos interesses daqueles que têm situação econômica e política mais abastada, ofertando o ensino propedêutico liceal no qual os 
estudantes têm acesso aos conhecimentos sobre arte, cultura, humanidades. A esses estudantes é possibilitado o acesso ao ensino superior, e lhes são oportunizadas as condições para cursarem uma graduação. Do outro lado está a Educação Profissional que visa atender às demandas econômicas de cada época ofertando o ensino utilitário, voltado para o 'saber fazer', sendo eminentemente prático para desenvolver a destreza manual, destinado aos estudantes das classes mais desfavorecidas. Essa dualidade reforça a divisão social não apenas no perfil dos estudantes que frequentam cada uma das escolas, mas também no próprio papel que a escola desempenha como meio de manter tal divisão.

A Educação Profissional (EP) como parte do processo educativo tem a finalidade de preparar os estudantes para o exercício de profissões, contribuindo para que o cidadão possa se inserir e atuar no mundo do trabalho e na vida em sociedade. Se a EP visa à preparação para o mundo do trabalho, nada mais coerente como atender às demandas exigidas pelo trabalho em cada momento histórico. O que pesquisadores, ao longo do tempo, questionam é que tipo de interesses estão contidos nas políticas educacionais para materializar essa educação que é ofertada aos estudantes. Interesses que contemplam a formação humana, a formação integral do estudante, ou os interesses que movem os objetivos do modo de produção capitalista.

Um dos pesquisadores que estuda a EP é Frigotto. Ele afirma que, de acordo com a classe dominante, a educação para os trabalhadores deve acontecer com a finalidade de habilitálos técnica e socialmente para o mercado de trabalho, subordinando assim a educação, para corresponder às demandas do capital, e o autor ainda completa que isso não é um fato novo, e que, de acordo com as novas tendências do capital, novas forma de adaptação na educação da classe trabalhadora também ocorrem, para assim continuar o ciclo de exploração da massa trabalhadora (FRIGOTTO, 1995).

Na mesma direção, Dermeval Saviani, em seu livro "O legado educacional do século XX no Brasil", corrobora afirmando:

A subordinação da educação ao desenvolvimento econômico significava torná-la funcional ao sistema capitalista, isto é, colocá-la a serviço dos interesses da classe dominante, uma vez que, qualificando a força de trabalho, o processo educativo concorria para o incremento da produção da mais valia. (SAVIANI, 2004, p. 48).

Na LDB, Lei n 9.394/1996, o seu artigo 22 apresenta as finalidades da educação básica: “desenvolver o educando, assegurar-lhe a formação comum indispensável para o exercício da cidadania e fornecer-lhe meios para progredir no trabalho e em estudos posteriores" (BRASIL, 1996). De acordo com esse artigo da lei, a educação básica tem por finalidade primeiramente 
formar o cidadão, dando-lhe condições para exercer a cidadania, e entende-se que esse exercício da cidadania é que vai possibilitar ao mesmo ter os meios para exercer uma profissão e progredir nos estudos, se assim o desejar. Pode-se notar que essa finalidade não é observada nos documentos normativos. No entanto, pesquisas mostram que a formação do estudante para o exercício da cidadania é possível se levarmos em conta o trabalho como princípio educativo. Aqui não se trata apenas de aprender e exercer uma profissão, mas compreender todo o processo pelo qual ocorre a produção e como se organiza na sociedade o emprego da força de trabalho. A integração entre o ensino e o trabalho é uma possibilidade de o estudante compreender o contexto no qual vive e exerce a sua função na vida e no trabalho.

Moura (2007, p. 22) afirma que o trabalho como princípio educativo "permite uma compreensão do significado econômico, social, histórico, político e cultural das ciências e das artes". Para o autor, há a "necessidade de uma reflexão sobre o mundo do trabalho, da cultura desse trabalho, das correlações de força existentes, dos saberes construídos a partir do trabalho e das relações sociais que se estabelecem na produção". Moura considera que o princípio educativo não se limita a aprender trabalhando ou trabalhar aprendendo, mas está relacionado com a

[...]intencionalidade de que através da ação educativa os indivíduos/coletivos compreendam, enquanto vivenciam e constroem a própria formação, o fato de que é socialmente justo que todos trabalhem, porque é um direito subjetivo de todos os cidadãos, mas também é uma obrigação coletiva porque a partir da produção de todos se produz e se transforma a existência humana e, nesse sentido, não é justo que muitos trabalhem para que poucos enriqueçam cada vez mais, enquanto outros se tornam cada vez mais pobres e se marginalizam - no sentido de viver à margem da sociedade. (MOURA, 2007, p. 22).

Nessa perspectiva, a formação voltada para a cidadania é uma formação ampla, na qual o cidadão enquanto sujeito profissionalmente capacitado, com um perfil formado por sólido embasamento científico, seja capaz de gerir e administrar novas demandas produzidas pelo contexto social e econômico, e que, acima de tudo, venha a ser um cidadão que saiba se posicionar conscientemente na sociedade a respeito do trabalho que exerce.

\section{Formação para o exercício da cidadania: o que diz a legislação}

No Brasil, o Decreto $n^{\circ} 5.154$, de 23/07/2004, em seu artigo $2^{\circ}$ que trata das premissas da Educação Profissional, no inciso III, estabelece "a centralidade do trabalho como princípio educativo" (BRASIL, 2004) quando legisla sobre a integração da educação profissional com o ensino médio. Concordamos com Ciavatta (2005), quando afirma que a formação integrada da 
EP com o ensino médio busca uma resposta às demandas do mundo do trabalho, constituído pela presença da ciência e da tecnologia enquanto forças produtivas que impulsionam a obtenção de lucros. Para a autora, o que "se busca é garantir ao adolescente, ao jovem e ao adulto trabalhador o direito a uma formação completa para a leitura do mundo e para a atuação como cidadão pertencente a um país, integrado dignamente à sua sociedade política" (CIAVATTA, 2005, p. 3).

O referido Decreto traz a possibilidade de prosseguimento nos estudos no âmbito da graduação, torna possível os itinerários formativos, permite a articulação com o ensino médio, especialmente de forma integrada ou concomitante. Cabe destacar que o Decreto $\mathrm{n}^{\circ}$ 8.268/2014 define a centralidade do trabalho como princípio educativo e a indissociabilidade entre teoria e prática (BRASIL, 2014). Observa-se na legislação a viabilidade do ensino integrado vir a ser uma possibilidade de formação ampla, integral, humanística, valorizando a cultura geral e técnica, ao mesmo tempo.

Após treze anos da publicação do Decreto foi aprovada a Lei no $13.415 / 2017$, que institui a Política de Fomento à Implementação de Escolas de Ensino Médio em Tempo Integral (BRASIL, 2017). Segundo Ferreti (2018), a Lei $n^{\circ} 13.415 / 2017$ tem por objetivo tornar o currículo mais flexível para, dessa forma, melhor atender aos interesses dos alunos do ensino médio. O autor afirma ainda que as "propostas centrais giram em torno de dois aspectos principais: a flexibilização curricular e a oferta de cursos em tempo integral (sete horas diárias)" (FERRETI, 2018, p. 27). Para ele a legislação

[...] parece ignorar que a divisão das atuais matrizes curriculares em um núcleo comum e uma parte diversificada, tendo em vista o atendimento a demandas locais por parte das escolas, devidas à extensão e diversidade cultural do país, já se constitui, em certo sentido, numa forma de flexibilização, aceita e praticada pelas escolas brasileiras desde a década de 1980, a qual não priva os estudantes do acesso ao conjunto de conhecimentos ofertados a partir de vários campos do conhecimento historicamente produzido. (FERRETI, 2018, p. 27).

Em relação à formação do estudante, a referida Lei dispõe em seu artigo 35-A, § $7^{\circ}$, que "os currículos do ensino médio deverão considerar a formação integral do aluno, de maneira a adotar um trabalho voltado para a construção de seu projeto de vida e para sua formação nos aspectos físicos, cognitivos e socioemocionais" (BRASIL, 2017).

Observa-se nesse excerto uma possibilidade de formação ampla, integral, humanística, valorizando a cultura geral e técnica, ao mesmo tempo. Ferreti (2018, p. 35) adverte que a escola não pode ser vista apenas como "formadora de sujeitos eficientes e pouco questionadores", mas como instituição que também forme os sujeitos “capazes de entender [...] tanto a sociedade em 
que vivem quanto a forma pela qual se estrutura o trabalho que realizam, tendo em vista a construção de formas mais humanas e igualitárias de produzir e viver".

Já em Portugal, o Ensino Secundário passou a ser obrigatório, universal e gratuito a partir de 2009, com a Lei $\mathrm{n}^{\circ}$ 85/2009, de 27 de agosto. Dentre os objetivos para o Ensino Secundário a Lei de Bases do Sistema Educativo apresenta o de "assegurar o desenvolvimento do raciocínio, da reflexão e da curiosidade científica e o aprofundamento dos elementos fundamentais de uma cultura humanística, artística, científica e técnica que constituam suporte cognitivo e metodológico apropriado para o eventual” (PORTUGAL, 2009).

Assegurar aos estudantes que saíram do ensino básico com aproveitamento o acesso à formação, seja no âmbito do prosseguimento nos estudos ou ao ensino profissional, é uma das finalidades do Ensino Secundário. Ao observar o objetivo constante no parágrafo anterior, vislumbra-se a possibilidade de ensino por meio do princípio educativo defendido por Saviani (2003). O objetivo contempla a formação de uma cultura humanística, artística e científica que possibilita ao estudante compreender o contexto econômico e social no qual está inserido, saber posicionar-se diante desse contexto no entendimento dos seus deveres e na busca de seus direitos. Observa-se ainda que o aprofundamento dos conhecimentos técnicos é contemplado no objetivo, uma vez que este é um insumo para que o estudante venha a ser um profissional que desenvolva seu trabalho de forma consciente; ou seja, se disponham os meios para a orientação e a formação profissional do estudante, possibilitando a preparação técnica e tecnológica, viabilizando a entrada no mundo do trabalho.

A promoção de um ensino de qualidade que contemple a formação humanística assim como a formação para o mundo do trabalho implica em materializar-se em aprendizagens efetivas e significativas no âmbito da escola. Faz-se necessário potencializar meios para o desenvolvimento de competências que contribuam para a formação cidadã e que ela se consolide em ações de sucesso no contexto dos desafios que são colocados pela sociedade atual. Uma das formas de materializar essa formação integral é observada no documento recente publicado no Diário da República, nº 129, de 6 de julho de 2018, o Decreto-Lei nº 55/2018, em Portugal.

O Decreto-Lei n 55/2018 (PORTUGAL, 2018) dispõe que "é necessário desenvolver nos alunos competências que lhes permitam questionar os saberes estabelecidos, integrar conhecimentos emergentes, comunicar eficientemente e resolver problemas complexos". Nos parágrafos introdutórios, o texto legal continua afirmando que para que haja uma operacionalização do perfil de competências que se pretende que os estudantes "desenvolvam, para o exercício de uma cidadania ativa e informada ao longo da vida, implica que seja dada às 
escolas autonomia para um desenvolvimento curricular adequado a contextos específicos e às necessidades dos seus alunos". Em seu artigo $3^{\circ}$, alínea c, define autonomia e flexibilidade curricular "como a faculdade conferida à escola para gerir o currículo dos ensinos básico e secundário, partindo das matrizes curriculares base[...]", contemplando "possibilidade de enriquecimento do currículo com os conhecimentos, capacidades e atitudes que contribuam para alcançar as competências previstas no Perfil dos Alunos à Saída da Escolaridade Obrigatória"2.

A autonomia e a flexibilidade curricular no Ensino Secundário correspondem a 25\% do total da carga horária dos componentes sociocultural e científico previstos para o ciclo de formação, no caso das matrizes com organização por ciclo de formação, conforme alínea b, do artigo $12^{\circ}$ do Decreto-Lei n ${ }^{\circ} 55 / 2018$. A autonomia e a flexibilidade na organização do currículo pela escola, no Ensino Secundário deve obedecer às orientações da matriz curricular-base que contempla um conjunto de disciplinas comuns nos componentes de formação dos cursos científico-humanísticos, nos cursos artísticos especializados e nos cursos profissionais (PORTUGAL, 2018).

O planejamento do currículo em cada escola deve considerar o conhecimento específico da comunidade em que está inserida, tendo como finalidade a adequação e a contextualização do currículo ao projeto educativo da escola, também devendo levar em conta as características dos alunos, conforme artigo $18^{\circ}$ do referido Decreto-Lei. O que se observa no conteúdo do documento é que as principais decisões a nível curricular são tomadas pelas escolas e pelos professores. A autonomia e a flexibilidade curricular expressas no documento desafiam as escolas e os seus professores a estabelecer um diálogo com a comunidade escolar e extraescolar, no sentido de construir e materializar um currículo que atenda às especificidades de cada curso.

Nesse sentido, o papel conferido à escola e aos professores no processo educativo dos estudantes deixa o Ministério da Educação como um coadjuvante, assumindo uma participação secundária nesse processo. O Ministério da Educação se consolida apenas como um mecanismo de apoio e acompanhamento do trabalho que as escolas desenvolvem. Por outro lado, estão as escolas e os professores que têm liberdade de ação frente à construção desse percentual de $25 \%$ do currículo. É a oportunidade de construir juntamente com a comunidade escolar um projeto curricular que responda às necessidades educativas e formativas e as expectativas dos estudantes e suas famílias, assim como atenda às exigências da sociedade.

\footnotetext{
${ }^{2}$ Documento referência para a organização de todo o sistema educativo, contribuindo para a convergência e a articulação das decisões inerentes às várias dimensões do desenvolvimento curricular. Disponível em: https://www.dge.mec.pt/sites/default/files/Curriculo/Projeto_Autonomia_e_Flexibilidade/perfil_dos_alunos.pdf
} 
A liberdade conferida às escolas para a implementação curricular apresenta alguns desafios. Um dos desafios que se apresenta é esse: para que o projeto curricular construído pela escola seja concretizado e apresente resultados satisfatórios necessita de um suporte organizacional que potencialize a formação de agrupamentos flexíveis dos alunos, a construção dos projetos de gestão integrada do currículo e a formação de grupos multidisciplinares de professores, conforme apontam Formosinho e Machado (2009).

A autonomia para a construção e implementação de um currículo com um percurso significativo, contextualizado, atendendo às expectativas de formação integral e construção da cidadania, passa pela capacidade da escola em se organizar, da cooperação dos professores e de outros profissionais envolvidos no processo educativo, na formação dos professores e no percurso construído, respeitando a individualidade de cada um. Ou seja, a flexibilização e a autonomia curricular que se traduzam em aprendizagem com resultados positivos está em estreita relação com a capacidade dos professores em refletir sobre o conjunto de fatores que fazem parte do perfil profissional e do entendimento das práticas pedagógicas e das condições nas quais tais práticas se materializam. Constitui um razoável desafio para as políticas educacionais, para a organização e gestão das escolas, para a ação profissional dos professores e para a comunidade escolar de forma geral, afirma Roldão (2009).

\section{Considerações Finais}

A trajetória da Educação Profissional no Brasil e em Portugal apresenta alguns pontos em comum. Inicialmente, Portugal, na condição de colonizador de uma colônia na América do Sul, inicia seus primeiros passos na EP com a Reforma Pombalina. Essa reforma foi impulsionada pelo contexto político e econômico da Inglaterra que já se mostrava, a partir dos séculos XVI e XVII, uma nação burguesa e industrial à frente das demais nações. A Reforma Pombalina visava colocar o reino português em patamares econômicos que viabilizassem as condições para que Portugal pudesse competir com as nações estrangeiras, e nada mais conveniente do que usar a sua maior colônia, o Brasil, para o alcance desse objetivo.

Outra situação semelhante envolvendo o Brasil e Portugal é que os dois países passaram por um período de ditadura. Portugal, em 1926, sofre um golpe militar que originou um novo regime e a ditadura. $\mathrm{O}$ ensino sofreu alterações, principalmente no caráter ideológico, baseado em forte doutrinação de caráter moral. Esse período se prolonga até 1933 quando se dá a fundação do Estado Novo. No Estado Novo, a crença na escola enquanto mecanismo utilizado para incrementar a produtividade econômica foi um fator recorrente, pois ao generalizar os 
conhecimentos contribuiu para a geração de riqueza no setor econômico. No Brasil, a década de 1930 foi um período de grandes transformações políticas. Getúlio Vargas assume o governo e permanece no poder durante quinze anos. Nesse período, a Educação Profissional foi legitimada pela Reforma Capanema, por meio das Leis Orgânicas do Ensino (1942), e foi criado o Ministério da Educação e Saúde Pública. Os documentos normativos da época atendiam às necessidades crescentes de preparação profissional do trabalhador para ofícios e técnicas decorrentes da industrialização.

A dualidade de oferta de ensino também se observa nos documentos normativos que tratam da Educação Profissional no Brasil e em Portugal. Os documentos, já relacionados no decorrer do texto, apresentam as políticas de educação como instrumentos que legitimam um hiato entre a educação pensada para a elite e a educação pensada para aqueles desprovidos economicamente. Essa última visa à formação de um exército de trabalhadores necessários à construção dos meios para se obter a riqueza potencial da nação em benefício dos que detêm o domínio dessa riqueza.

No entanto, observa-se também que os dois países apresentam políticas educacionais atuais que possibilitam a Educação Profissional, uma formação que não se restrinja apenas à preparação técnica do estudante para atuar no mercado de trabalho, contribuindo para o setor produtivo. No Brasil, o estudante que já tenha concluído o ensino fundamental pode cursar o ensino médio integrado à educação profissional, ou seja, habilitar-se a uma profissão técnica de nível médio, e concluir o ensino médio, na mesma instituição de ensino, contando com matrícula única para cada aluno. Essa forma de acesso ao ensino médio integrado à educação profissional é regulamentada pelo Decreto $\mathrm{n}^{\circ}$ 5.154/04, permitindo aos jovens maiores possibilidades de entendimento do mundo em que vivem, observando a premissa de centralidade do trabalho como princípio educativo, sustentado por Saviani (2003) em suas pesquisas. Ao considerar a educação profissional como uma imposição da realidade, uma necessidade do homem para sua atuação no mundo e gerar a sua subsistência, os autores afirmam que

[...] o que se persegue não é somente atender a essa necessidade, mas mudar as condições em que ela se constitui, é também uma obrigação ética e política, garantir que o ensino médio se desenvolva sobre uma base unitária para todos. Portanto, o ensino médio integrado ao ensino técnico, sob uma base unitária de formação geral, é uma condição necessária para se fazer a "travessia" para uma nova realidade. (FRIGOTTO; CIAVATTA; RAMOS, 2005, p. 49).

A defesa do ensino médio integrado à educação profissional, constituída pelo entendimento do trabalho, ciência e tecnologia e cultura, busca a superação ou a minimização 
do histórico conflito existente entre o papel da escola em formar para o exercício da cidadania ou apenas para o atendimento às demandas do setor produtivo.

Em Portugal, o sistema educativo aponta a possibilidade de minimizar a dicotomia entre o ensino liceal e a educação profissional, ao assegurar às escolas a autonomia e flexibilização na construção de $25 \%$ do currículo a partir de uma matriz curricular-base constituída por um conjunto de disciplinas comuns nos componentes de formação geral, nos cursos científicohumanísticos e nos cursos artísticos especializados bem como nos cursos profissionais, conforme publicado no Decreto-Lei $\mathrm{n}^{\circ}$ 55, de 6 de julho de 2018. A escola, ao planejar o currículo a ser utilizado, deve considerar o conhecimento específico da comunidade em que a escola se insere, tendo como finalidade a adequação e contextualização do currículo ao projeto educativo da escola e às características dos alunos. É o que reza o artigo $18^{\circ}$ do acima mencionado documento legal.

Em relação a isso, Joaquim Machado, em seu texto “Organização e currículo: em busca de um modelo alternativo", se posiciona a respeito dessa autonomia e flexibilidade permitida à escola e sua comunidade na construção e materialização do currículo. Para o autor, a “autonomia da escola não se altera com as alterações legislativas, mas depende sobretudo do processo pelo qual cada escola e seus professores a vão construindo e, desse modo, apresentam um percurso orientado para a diversificação e a flexibilização (MACHADO, 2017, p. 31). O autor continua afirmando que a "autonomia é mais um processo de construção coletiva do que um artefacto legislativo que o determina e requer mais autoria do que ação em conformidade" (p. 31). A autonomia e a flexibilização curricular dependem da concepção que a organização escolar no âmbito da escola tem em relação à sociedade que temos e a coerência entre a sociedade que se quer e que escola serve a essa concepção. Quais são os caminhos que cada escola escolhe, em seu planejamento, para a concretização da sociedade que queremos, e que cidadãos vão atuar na construção dessa sociedade.

Conclui-se que o ensino médio integrado à educação profissional, no Brasil, e a autonomia e flexibilização curricular, em Portugal, permitem melhor desenvolvimento dos adolescentes, jovens e adultos na sua capacidade de interagir com o mundo em que vivem, viabilizando as condições para se desenvolverem de forma plena, sendo preparados para o mundo do trabalho, e ao mesmo tempo preparados em conteúdos sociais, culturais e tecnológicos. Nesse sentido, importa acrescentar que não basta a prescrição contida na legislação visando à formação das bases científicas e humanas, seja por meio da autonomia em construir o currículo ou a possibilidade de formação do ensino médio integrado à educação 
profissional. A materialização da formação integral do estudante está relacionada e depende das condições que são dadas às escolas para exercerem plenamente o seu papel.

\section{REFERÊNCIAS}

AZEVEDO, Joaquim. Ensino profissional em Portugal, 1989-2014: os primeiros vinte e cinco anos de uma viagem que trouxe o ensino profissional da periferia para o centro das políticas educativas. 2014. Disponível em:

http://www.joaquimazevedo.com/Images/BibTex/Escolas_profissionais_Livro_VFinal.pdf. Acesso em: 10 jan. 2019.

BASTOS, Pedro P. Z. Qual era o projeto econômico varguista?. Estud. Econ., São Paulo, v. 41, n. 2, p. 345-382, jun. 2011.

BRASIL. Decreto n ${ }^{\circ} 7.566$, de 23 de setembro de 1909. Crêa nas capitaes dos Estados da Republica Escolas de Aprendizes Artifices, para o ensino profissional primario e gratuito. Diário Official - 26/9/1909, Página 6975 (Publicação Original). Disponível em: http://www2.camara.leg.br/ legin/fed/decret/1900-1909/decreto-7566-23-setembro-1909525411 publicacaooriginal-1-pe.html. Acesso em: 15 jan. 2020.

BRASIL. Constituição de 1937. Brasília: Diário Oficial da União - Seção 1 - 10/11/1937, Página 22359 (Publicação Original). Disponível em: https://www2.camara.leg.br/legin/fed/consti/1930-1939/constituicao-35093-10-novembro1937-532849-publicacaooriginal-15246-pl.html. Acesso em: 17 jan. 2020.

BRASIL. Decreto-Lei n 4.073, de 30 de janeiro de 1942. Lei Orgânica do Ensino Industrial. Coleção de Leis do Brasil, Rio de Janeiro, p. 1, 31 dez. 1942. Disponível em: http://www2.camara.leg.br/legin/fed/declei/1940-1949/decreto-lei-4073-30-janeiro-1942414503-publicacaooriginal-1-pe.html. Acesso em: 2 jun. 2015.

BRASIL. Lei no 4.024, de 20 de dezembro de 1961. Fixa as diretrizes de bases da Educação Nacional, e dá outras providencias. Diário Oficial da União. Brasília, 20 dez., 1961. Disponível em: http://www.planalto.gov.br/CCIVIL_03/leis/L4024.htm. Acesso em: 3 jun. 2015.

BRASIL. Lei Federal no 5.692, de 11 de agosto de 1971. Fixa Diretrizes e Bases para o ensino de $1^{\circ}$ e $2^{\circ}$ graus, e dá outras providências. Diário Oficial da União - Seção 1 - 12/8/1971, Página 6377 (Publicação Original). Disponível em: https://www2.camara.leg.br/legin/fed/lei/1970-1979/lei-5692-11-agosto-1971-357752-normapl.html. Acesso em: 2 abr. 2015.

BRASIL. Lei n ${ }^{\circ}$ 9.394, de 20 de dezembro de 1996. Estabelece as diretrizes e bases da educação nacional. Diário Oficial da União. Brasília, 21 dez., 1996. Disponível em: http://www.planalto.gov.br/ccivil_03/LEIS/L9394.htm. Acesso em: 20 maio 2015.

BRASIL. Decreto $\mathrm{n}^{\circ} 2.208$, de 17 de abril de 1997. Regulamenta o $\S 2^{\circ}$ do art. 36 e os arts. 39 a 42 da Lei $n^{\circ}$ 9.394, de 20 de dezembro de 1996, que estabelece as diretrizes e bases da educação nacional. Diário Oficial da União, Brasília, 18 abr. 1997. Disponível em: http://www.planalto.gov.br/ccivil_03/decreto/D2208.htm. Acesso em: 2 jun. 2015. 
BRASIL. Decreto no 5.154, de 23 de julho de 2004. Regulamenta o art. 36 e os artigos 39 a 41 da Lei $n^{\circ}$ 9394/1996. Senado Federal. Subsecretaria de Informações. Disponível em: http://www6.senado.gov.br/sicon. Acesso em: 28 jan. 2020.

BRASIL. Ministério da Educação. Lei no 11.892/2008. Diário Oficial da União, Brasília, p. 1, 2008. Disponível em: http://www.planalto.gov.br/ccivil_03/_ato20072010/2008/lei/l11892.htm. Acesso em: 10 jun. 2015.

BRASIL. Lei $\mathrm{n}^{\circ}$ 12.513, de 26 de outubro de 2011. Diário Oficial da União, Brasília, p. 1, 27 out. 2011. Disponível em: http://www.planalto.gov.br/ccivil_03/_ato20112014/2011/lei/112513.htm. Acesso em: 20 jan. 2015.

BRASIL. Decreto ${ }^{\circ} 8.268$, de 18 de junho de 2014. Altera o Decreto $\mathrm{n}^{\circ}$ 5.154, de 23 de julho de 2004, que regulamenta o $\S 2^{\circ}$ do art. 36 e os arts. 39 a 41 da Lei ${ }^{\circ} 9.394$, de 20 de dezembro de 1996. Diário Oficial da União - Seção 1 - 20/6/2014, Página 18 (Publicação Original). Disponível em: https://www2.camara.leg.br/legin/fed/decret/2014/decreto-8268-18junho-2014-778943-norma pe.html\#:

$\sim:$ text=EMENTA\%3A\%20Altera\%20o\%20Decreto\%20n\%C2\%BA,20\%20de\%20dezembro $\% 20 \mathrm{de} \% 201996$. Acesso em: 10 jun. 2015.

CARNEIRO, Roberto. A educação primeiro. Vila Nova de Gaia: FML, 2004.

CIAVATTA, Maria. A formação integrada: a escola e o trabalho como lugares de memória e identidade. 2005. Disponível em: http://www.uff.br/trabalhonecessario/images/TN_03/TN3CIAVATTA.pdf. Acesso em: 21 dez. 2017.

CIAVATTA, Maria; RAMOS, Marise. Ensino Médio e Educação Profissional no Brasil: Dualidade e Fragmentação. Revista Retratos da Escola, Brasília, v. 5, n. 8, p. 27-41, jan./jun. 2011.

FERRETTI, Celso J. A reforma do Ensino Médio e sua questionável concepção de qualidade da educação. Estud. av. [online], 2018, vol. 32, n. 93.

FONSECA, Sonia M. O ensino profissional no Brasil colônia: a proposta de três planos de estudos e ensino-Nóbrega, Pombal e Lebreton. In: BATISTA, Eraldo L.; MULLER, Meire T. (Orgs.). A Educação Profissional no Brasil: história, desafios e perspectivas para o século XXI. Campinas, SP: Alínea, 2013.

FORMOSINHO, João; MACHADO, Joaquim. Equipas educativas: Para uma nova organização da escola. Porto: Porto Editora, 2009.

FRIGOTTO, Gaudêncio. Educação e a crise do capitalismo real. São Paulo: Cortez, 1995.

FRIGOTTO, Gaudêncio; CIAVATTA, Maria; RAMOS, Marise. Ensino médio integrado concepções e contradições. São Paulo: Cortez, 2005.

GARCIA, N. M. D. (Org.) ; LIMA FILHO, D. L. (Org.) . Trabalho, educação e tecnologia: alguns de seus enlaces. Curitiba: Editora da UTFPR, 2010. v. 1. 198p 
GOMES, Hélica S. C. Os modos de organização e produção do trabalho e a Educação Profissional no Brasil: uma história de dualismos e racionalidade técnica. In: BATISTA, Eraldo L.; MULLER, Meire T. (Orgs.). A Educação Profissional no Brasil: história, desafios e perspectivas para o século XXI. Campinas, SP: Alínea, 2013.

JUSTINO, José D. Lei de Bases do Sistema Educativo: balanço e prospetiva - Volume I. Coleção: Seminários e Colóquios. CANELAS, Ana et al. (Orgs.). Conselho Nacional de Educação, Portugal, 2017.

KUENZER, Acacia. Ensino médio e profissional: as políticas do estado neoliberal. v. 63, 4. ed. São Paulo: Cortez, 2007.

MACHADO, Joaquim. Organização e currículo: em busca de um modelo alternativo. In: Construir a autonomia e a flexibilização Curricular: os desafios da escola e dos professores. Universidade Católica/ Editora Porto, 2017.

MARTINS, António M.; PARDAL, Luís A.; DIAS, Carlos. Ensino técnico e profissional: natureza da oferta e da procura. Interações. Disponível em: https://revistas.rcaap.pt/interaccoes/article/view/283. Acesso em: 20 jan. 2020.

MARTINS, Ernesto C.; MARTINS, Susana I. B. A visão do ensino técnico profissional português: evolução histórica das medidas e rupturas. B. Téc. Senac, Rio de Janeiro, v. 42, n. 2, p. 6-31, maio/ago. 2016.

MONTI, Ednardo M. G. do. Aulas régias: luz que emana do trono. Quaestio, Sorocaba, SP, v. 20, n. 1, p. 73-89, abr. 2018.

MOURA, Dante H. Educação básica e Educação profissional: dualidade histórica e perspectivas de integração. Holos, ano 23, v. 2, 2007.

PORTUGAL. Alvará régio de 1759. Lisboa, 1759. Disponível em: http://193.137.22.223/fotos/editor2/RDE/L/S18/1751_1760/1759_06_28_alvara.pdf. Acesso em: 17 fev. 2020.

PORTUGAL. Decreto de 1852-12-30: cria o ensino industrial. Diário do Governo, Lisboa, n. $1-2,1 / 2$ jan. 1853.

PORTUGAL. Decreto $\mathrm{n}^{\circ}$ 5.029. Organização do ensino industrial e comercial. Diário do Governo, Lisboa, n. 263, 5 dez. 1918. 1. Série, p. 2067-2112.

PORTUGAL. Constituição da República Portuguesa (CFP) de 1976. Diário da República Eletrónico. Acesso em: $1^{\circ}$ out. 2018.

PORTUGAL. Ministério da Educação. Lei de Bases do Sistema Educativo. Lei no 49/2005, de 30 de agosto, Portugal. Disponível em:

http://www.pgdlisboa.pt/leis/lei_mostra_articulado.php?nid=1746\&tabela=leis. Acesso em: $1^{\circ}$ out. 2018.

PORTUGAL. Ministério da Educação. Lei no 85/2009, de 27 de agosto. Diário da República, $1^{\text {a }}$ série, $\mathrm{n}^{\circ}$ 166, 27 de agosto de 2009. 
PORTUGAL. Decreto-Lei no 55/2018. Diário da República, nº 129, 6 de julho de 2018.

RODRIGUES, Liliana. O ensino técnico-profissional em Portugal. Revista da Faculdade de Educação, ano VIII, n. 14, jul./dez. 2010.

ROLDÃO, Maria do C. Estratégias de ensino: o saber e o agir do professor. Gaia: Fundação Manoel Leão, 2009.

SAVIANI, Dermeval. O choque teórico da politecnia. Trabalho, educação e saúde, v. 1, n. 1, p. 131-152, 2003.

SAVIANI, Dermeval. O legado educacional do "longo século XX" brasileiro. In: SAVIANI, Dermeval et al. O legado educacional do século XX no Brasil. Campinas, SP: Autores Associados, 2004.

SAVIANI, Dermeval. História das ideias pedagógicas no Brasil. Campinas, SP: Autores Associados, 2007.

SCHWARTZMAN, Simon; BOMENY, Helena M. B.; COSTA, Vanda M. R. Tempos de Capanema. Editora da Universidade de São Paulo e Editora Paz e Terra, 2000.

SECO, Ana P.; AMARAL, Tania C. I. do. Marquês de Pombal e a reforma educacional brasileira. HISTEDBR, Faculdade de Educação, Campinas, SP. Disponível em: http://www.histedbr.fe.unicamp.br/navegando/periodo_pombalino_intro.html. Acesso em: 20 jan. 2020.

\section{SOBRE AS AUTORAS:}

\section{Valdivina Alves Ferreira}

Doutora em Educação, Pontifícia Universidade Católica de Goiás (PUC-Goiás); Docente no Programa de Pós-Graduação em Educação - Mestrado e Doutorado - Universidade Católica de Brasília (UCB), Brasília/DF; Grupo de Estudos e Pesquisas: Políticas Públicas Educacionais no âmbito da educação básica. E-mail: valdivina5784@ hotmail.com

iD https://orcid.org/0000-0002-2306-7465

\section{Luísa Cerdeira}

Doutora em Ciências da Educação, Políticas de Especialidade e Organização do Sistema Educacional, (Faculdade de Psicologia e Ciências da Educação da Universidade de Lisboa). Coordenação do Grupo de Missão da Internacionalização do IE-ULisboa - Instituto de Educação, Universidade de Lisboa; Membro do Conselho de Gestão do IE-Ulisboa; Presidente da Assembleia Geral da FORGES (Fórum da Gestão do Ensino Superior nos Países e Regiões de Língua Portuguesa). E-mail: luisa.cerdeira@ie.ulisboa.pt

iD https://orcid.org/0000-0002-2217-7822

Recebido em: 22 de junho de 2020 Aprovado em: 21 de outubro de 2020 Publicado em: 01 de dezembro de 2020 